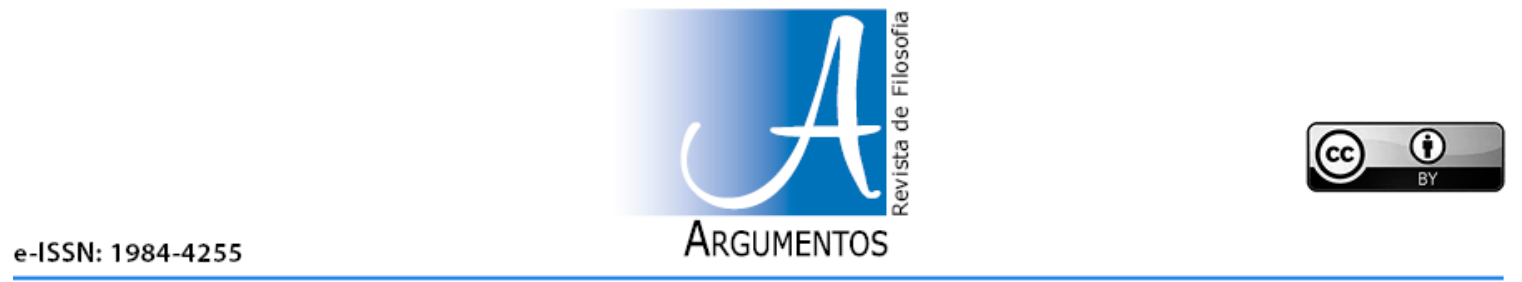

D0I: https://doi.org/10.36517/Argumentos.23.5

\title{
O discurso de Aristófanes no Banquete de Platão
}

\author{
The Aristophane's speech in Plato's symposium
}

\author{
Luiz Maurício Bentim da Rocha Menezes \\ https://orcid.org/0000-0003-4925-9876-E-mail: Imbrmenezes@yahoo.com.br
}

\begin{abstract}
RESUMO
O Banquete é a obra de Platão que fala sobre o Amor (Éros) por excelência. Nosso trabalho irá se centrar no discurso proferido por Aristófanes que, no intuito de falar de todos os amores possíveis entre os humanos, irá fazer aquele que seria o primeiro mito sobre gênero, isto é, o mito do andrógino. Será através desse mito que será possível se estabelecer um sentido para a plenitude do amor entre os homens ou, como preferimos dizer, um todo erótico que se forma a partir da divisão da humanidade em três gêneros diferentes. Aristófanes, dessa forma, consegue demonstrar o significado do amor da maneira mais ampla possível. Por fim, iremos confrontar o discurso aristofânico com a defesa do amor dada por Sócrates e a relação que ele estabelece entre o todo erótico e o Bem.
\end{abstract}

Palavras-chave: Banquete de Platão. Mito do Andrógino. Aristófanes. Sócrates. Amor.

\begin{abstract}
Plato's Symposium is about Love (Eros) par excellence. Our work will focus on the discourse uttered by Aristophanes that, in order to speak of all the possible loves among men, will make what would be the first myth about gender, that is, the myth of the androgynous. It will be through this myth that it will be possible to establish a sense for the fullness of love between men or, as we prefer to say, an erotic whole that is formed from the division of humanity into three different genres. Aristophanes, in this way, manages to demonstrate the meaning of love in the widest possible way. At the end, aristophanic discourse will be confronted with the defense of the love given by Socrates and the relation he establishes between the erotic whole and the Good.
\end{abstract}

Keywords: Plato's Symposium. Myth of Adrogynous. Aristophanes. Socrates. Love. 


\section{Introdução}

O discurso de Aristófanes no Banquete de Platão ${ }^{1}$ é um discurso um tanto singular. Aristófanes já havia passado sua vez de falar para Erixímaco por conta de um soluço que o impedia de falar. Esse recurso utilizado por Platão na cena dramática ordena os discursos proferidos sobre Éros, o Amor, dentro de uma ordem crescente dos assuntos que se vão acrescentando no diálogo como um todo. Erixímaco, corroborando a visão de Pausânias, teria defendido a existência de dois éros. Sendo ele médico, teria adequado o discurso sobre éros à linguagem médica, tomando um como sendo o éros doente, típico dos amantes que se perdem em seus amores excessivos e, o outro, o éros saudável, capaz de curar os males do excesso através da moderação. No entanto, para que seja possível estabelecer uma relação de saúde é preciso que haja a dosagem correta, isto é, a moderação de éros e isso só é possível através de uma arte (techné) capaz de dar a medida para o que se sente. Éros, portanto, na linguagem de Erixímaco, estabelece uma relação análoga com as artes, permitindo uma metrificação do amor.

Podemos notar que o amor, no discurso médico, deve ser administrado como um phármakon ${ }^{2}$. O médico oferece o phármakon/discurso para o doente que está tomado pela loucura erótica. Tal loucura instalada na alma deve ser administrada corretamente, mantendo-se o êxtase e sem ultrapassá-lo, pois, do contrário, este perece em sua loucura. O discurso amoroso deve ser administrado como um phármakon pela arte adequada para que o amante possa manter-se dentro da medida do amor e não cair no excesso do amor possesso que visa prejudicar todo e qualquer tipo de relação amorosa que possa vir a se estabelecer entre duas pessoas que se amam. Dessa forma, Erixímaco acaba por estabelecer a arte de amar que deve ser ministrada análoga a arte médica e que tem como paciente o amante. É a este que deve ser oferecido o phármakon discursivo para que o amante possa ter a medida adequada do amor.

Quando Erixímaco dá a vez a Aristófanes, este será alertado pelo médico para que não venha a dizer algo risível e estragar o andamento do discurso, no que Aristófanes irá rir e responder:

Tens razão Erixímaco; fica o dito pelo não dito. Porém não precisas vigiar-me; o que

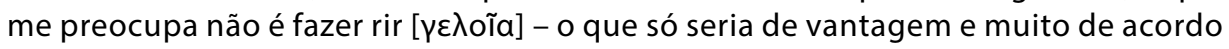

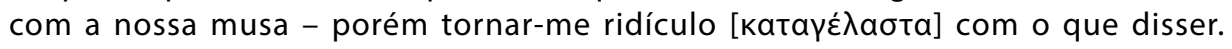
(Banquete, 189b4-7).

Aristófanes está pronto para fazer um discurso novo, totalmente diferente do que Erixímaco nos apresentou, algo de todo inédito para os convivas presentes no Banquete de Agatão e, talvez, para toda a Grécia da época retratada na obra. Aristófanes não está, de fato, preocupado se vai parecer ridículo aos demais. Sua arte é fazer rir e fazer rir é o seu ofício, portanto, se sua narrativa for um tanto ridícula, isso só irá beneficiar ainda mais a sua reputação. Seu discurso começa exaltando Éros como "um médico para males cuja cura definitiva redun-

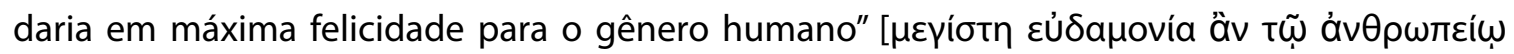

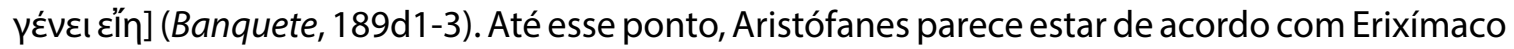
e não faz nada de anormal ou risível. No entanto, tudo muda quando ele nos diz que precisa

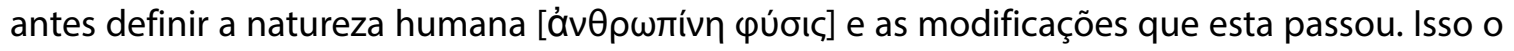
fará sair da linguagem médica para uma ordem metafísica.

\footnotetext{
1 Platão. O Banquete, 189c-193d. A maioria das referências ao 'Banquete' de Platão é da tradução de Carlos Alberto Nunes, O Banquete (Belém: EDUFPA, 2001). Para o texto grego, utilizamos a edição estabelecida por John Burnet, Platonis Opera, Tomvs II (Oxford: Oxford University Press, 1901), oferecendo nossa própria tradução deste se assim considerarmos necessário. Demais citações à obra serão abreviadas por Banquete.

2 Para maiores informações sobre a loucura erótica e sua função como um phármakon relacionada com a filosofia, ver Switzer, 1994, p. 27 et. seq.
} 
O mito do Andrógino se inicia com essa tentativa de definir qual seria a real natureza humana. É o primeiro mito sobre gênero que temos registro. Aristófanes usará esse mito para tentar dar conta do humano como um todo, falando de todos os tipos de amores possíveis e não somente um em específico. Ele começa dizendo que no princípio haviam três gêneros: masculino, feminino e o andrógino. Isso porque os homens seriam duplos, tendo duas cabeças, quatro pernas, quatro braços, etc. Os três gêneros representavam a forma completa da humanidade, sendo o masculino a junção de homem + homem, originando-se do sol, o feminino seria a junção da mulher + mulher, originando-se da terra e o andrógino, seria a junção de homem + mulher ${ }^{3}$, originando-se da lua. Essa caracterização do humano tem uma explicação marcante que só ficará clara a partir da penalidade imposta por Zeus à humanidade. Os homens ao tentarem desafiar os deuses terão como punição o enfraquecimento da espécie, dividindo-os no meio (Banquete, 190d). Dessa forma cada um dos gêneros será dividido e onde antes havia um, agora há dois. O que pretendemos investigar em nosso artigo é o sentido dessa busca da unidade das partes divididas por intermédio do mito apresentado por Aristófanes no Banquete.

\section{O mito do andrógino e o todo erótico do ser}

A punição divina sobre a humanidade dividiu todos aqueles que antes eram unos, deixando suas partes incompletas. Ou seja, o que antes formava um todo perfeito passou a ser uma parte imperfeita vagando no mundo. Aristófanes chama a atenção para o fato de que essa é a condição atual dos homens, mas não a sua verdadeira natureza, pois a natureza humana é, originariamente, una. Os humanos sem suas metades passam a morrer de fome ou de outras causas devido a saudade da parte que lhes falta. Para resolver esse problema e apiedando-se dos homens Zeus dará um sentido para éros, fazendo do desejo sexual esse resgate das partes separadas (Banquete, 191b-c). Será nesse ponto que Aristófanes irá iniciar a sua explicação para a existência de erós. Ele está a falar de todos os amores humanos possíveis, entendendo que a separação dos gêneros significa justamente isso. Entre aqueles que compunham o masculino, a divisão dará origem a dois homens que gostam de homens; entre os que compunham o feminino dará origem a duas mulheres que gostam de mulheres; e entre os que compunham o andrógino dará origem a um homem que gosta de mulher e uma mulher que gosta de homem. Dessa forma, Aristófanes pretende abarcar o todo das possibilidades amorosas entre os humanos. Éros tem papel fundamental para reunificar os homens e salvá-los da solidão a que foram condenados.

“Desde então é inato nos homens o amor de uns para os outros, o amor que reestabelece nossa primitiva natureza e que, no empenho de formar de dois seres um único, sana a natureza humana." (Banquete, 191c8-d3).

Aristófanes demonstra que a separação dos humanos levou com que eles anelassem o reencontro com a sua metade para novamente formar um todo. "O desejo desse todo e o em-

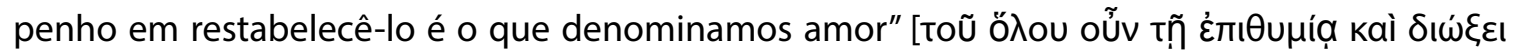

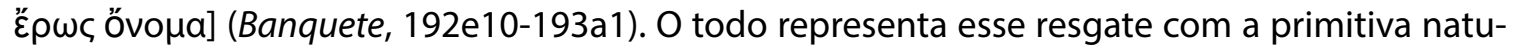
reza humana, pois os homens não são completos e por isso desejam unir-se uns aos outros. $O$ discurso de Aristófanes trata, em grande parte, da sensibilidade existente nas relações amorosos. Ao contrário dos outros discursos, Aristófanes não faz abstrações sobre éros, mas deixa

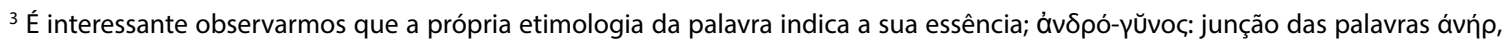

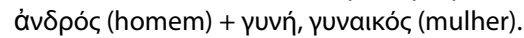


bem claro seu sentido como relação sexual. Éros é a força que liga os indivíduos uns aos outros pelo desejo. Segundo Dover:

A decisão de Platão no caso do discurso de Aristófanes está, eu sugiro, no valor compartilhado entre comédia e folclore e isto acontece, aparentemente, quando nós examinamos os mais importantes contrastes entre Aristófanes e os outros oradores no Banquete. Todos os outros oradores argumentam em algum grau de termos abstratos, mesmo se o argumento simula ele mesmo, na forma tradicional, como uma exposição dos atributos de um ser sobrenatural. Somente Aristófanes se compromete de todo o coração com o particular e o perecível; ele toma por certo que para uma reunião individual com seu único, sua individual 'outra metade' é um fim em si mesmo. Esta é a questão entre ele e Diotima. (DOVER, 1966, 47).

Apesar de concordarmos com Dover de que Aristófanes está comprometido com o particular representado no encontro entre dois indivíduos através da força erótica que os atrai, acreditamos que há uma explicação metafísica na formação desse todo erótico apresentado em seu discurso. A separação é ontológica: do um veio o múltiplo e o múltiplo anseia retornar ao um. Ao levantar uma hipótese mítica que explica a natureza humana, Aristófanes estaria engajado em apresentar uma proposta que explicasse éros em sua totalidade. No entanto, isso só poderia ser feito se houvesse um ponto de demarcação que expusesse os limites para se retomar a totalidade, e essa demarcação se dá com a punição divina dos homens que faz com que eles estejam sempre em busca desse reencontro com a unidade primordial da sua natureza. Isso fica claro quando ele afirma que

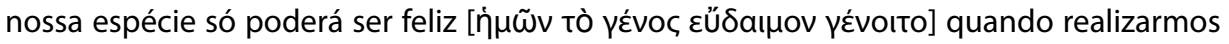
plenamente a finalidade do amor e cada um de nós encontrar o seu verdadeiro amado, retornando, assim, à sua primitiva natureza. Se isso for o que há de melhor [äpıotov], nas presentes circunstâncias o melhor, necessariamente [ávaүkaĩov], para cada um será o que mais aproxima-se desse desiderato, a saber: encontrar o amigo cuja natureza corresponda a suas aspirações. (Banquete, 193c3-8).

Aqui Aristófanes parece fazer uma relação entre o reestabelecimento da primitiva natureza e a felicidade humana. Há em éros uma força necessária [ảvaүkaĩov] que procura o caminho para o melhor [äpıotov], mas esse melhor é uma busca para "encontrar o amigo cuja natureza corresponda a suas aspirações". Essa é uma aspiração metafísica, pois envolve a busca por uma completude mítica que não existe na sensibilidade. Portanto, o resgate da unidade originária se faz através do todo erótico.

O todo erótico que estamos nos referindo é a maneira pela qual Aristófanes interpreta éros em seu discurso. Éros, além de ser uma força necessária que age na união dos homens, também representa a construção de uma relação amorosa e de parceria entre dois indivíduos. Para isso atentemos aos significados de éros presentes no discurso aristofânico ${ }^{4}$ :

1. Desejo sexual - Quando um indivíduo A deseja o indivíduo B pelas qualidade genericamente reconhecidas de $B$ e, por isso, A quer manter relações sexuais com $B$. Daqui $C$ pode entender porque $A$ deseja $B$; e quando confrontado com $D$, que possui qualidades objetivamente desejáveis em maior medida do que $B, A$ é provável que prefira $D$ a $B$. $O$ mote principal de éros aqui é o desejo.

2. Afeição - Algo que podemos sentir por alguém de qualquer idade ou gênero. O mote principal de éros aqui é a amizade.

\footnotetext{
${ }^{4}$ Utilizamos aproximadamente a interpretação de Dover (1966, p. 48-49). Segundo Dover, "Aristófanes usa a palavra [ह̌pwc] exclusivamente para (3)", o que discordamos, como pretendemos demonstrar em nosso trabalho.
} 
3. Preferência - Quando o desejo de A por B é 'preferência', muitas vezes acontece que B não é conspícuo para qualidades objetivamente desejáveis, que $C$ não entende por que A prefere $B$, e que a preferência de $A$ é inabalável pela acessibilidade do infinitamente desejável D. O mote principal de éros aqui é a escolha.

A completude só pode ser atingida entre os indivíduos através de relação entre esses três significados de éros. É nisso que consiste o todo erótico que estamos a falar em nosso trabalho. A unidade não é apenas o retorno a primitiva natureza retratada no mito, mas também o reconhecimento no outro desses três significados de éros. O primeiro significado implica em um desejo que se pode sentir por qualquer indivíduo que possui atributos genéricos socialmente reconhecidos. Devido a isso, (1) não é a garantia de um resgate com a primitiva natureza. O segundo significado é o fundamento da amizade (philía), ele implica em um reconhecimento mútuo entre as partes e um forte companheirismo. Apensar de (2) poder se relacionar com (1), ele não é uma necessidade e, portanto, (2) é possível de se ter com diferentes tipos de pessoas sejam elas do mesmo sexo, idade, grau de parentesco ou qualquer outro atributo. $O$ terceiro significado é basilar para a noção do todo erótico que estamos defendendo. A preferência por alguém é o atributo que relaciona todos os demais. (1), (2) e (3) estão ligados por causa de (3). É possível ter (1) ou (2) separados dos demais, mas não se é possível ter (3) sem ter (1) e (2). A preferência por alguém é a escolha que se faz de se estar com aquela pessoa independente dos atributos sociais que levariam normalmente ao sexo. Entretanto, essa não é qualquer escolha, como se faz ao se escolher uma marca de um produto qualquer, mas uma escolha erótica que envolve também um desejo pelo objeto amoroso. A preferência implica em um encontro de almas que vai muito além de qualquer atributo físico. É quando Aristófanes diz:

se quisermos celebrar a divindade a quem devemos tão grande benefício, teremos, com justiça, de fazer o elogio de Éros, que nos concede no presente o maior bem, com reconduzirnos ao que é próprio e nos dá a doce esperança de, para o futuro, nos mostrarmos reverentes aos deuses, reestabelecer nossa primitiva natureza, curar-nos e deixar-nos felizes e bemaventurados. (Banquete, 193c8-d5).

Somente através de (3) se pode ter o todo erótico, pois a preferência representa o reencontro das metades separadas reunidas na unidade primordial da natureza humana. É nisso que se encontra o sentido do amor no discurso de Aristófanes, que, ao querer exercer a sua musa e provocar o ridículo, acaba por fazer o mais belo dos discursos do Banquete. $O$ discurso aristofânico, além de envolver todos os gêneros possíveis, também é um discurso sobre o sentido do amor na vida dos homens rumo a plena felicidade.

\section{A parte, o todo e o bem: a escada erótica de Diotima}

Sócrates irá explicar no Banquete a relação que Éros possui com a beleza. O amor seria desejo de algo e, segundo ele, "[...] só pode haver amor do belo" (Banquete, 201a). Irá dizer também ser Éros não um deus, de fato, mas um Saímov (Banquete, 202d), um intermediário entre deuses e homens, e por isso mesmo não seria belo, mas amante por natureza da beleza. Será nesse ponto que Sócrates irá apresentar o mito do nascimento de Éros (Banquete, 203b-c), de modo a poder demonstrar a natureza do amor. No dia do nascimento de Afrodite, o deus Recurso teria bebido demais, penetrou no jardim de Zeus e adormeceu. Pobreza indo à festa para mendigar, acaba encontrando Recurso e se aproveita dele para fazer um filho. Éros seria, portanto, filho de Recurso (Póros) e Pobreza (Penía) e, dessa forma teria a característica de ambos em sua natureza: 
Tendo herdado a natureza da mãe, é companheiro eterno da indigência. Por outro lado, como filho de tal pai, vive a excogitar ardis para apanhar tudo o que é belo e bom; é bravo, audaz, expedito, excelente caçador de homens, fértil em ardis, desejoso da sabedoria

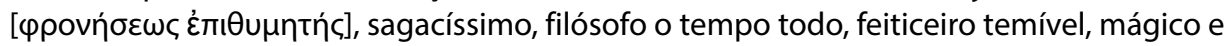
sofista. (Banquete, 203d3-8).

Éros é um mestre de muitos ardis, tendo as principais características do investigador. Seu desejo é pela phrónesis, pelo conhecimento pleno que ainda lhe falta e, por isso, ele se aproxima tanto do filósofo, mas também do mago e sofista, isto é, de todos aqueles que buscam a sabedoria nas suas artes. E aqui, provavelmente, se encontra o sentido de Platão colocar tanto na boca de Aristófanes como de Sócrates um mito, pois será na composição desses mitos que Platão pretende apresentar uma verossimilhança com o que há na natureza humana e sua relação com o amor. Entendemos aqui que o mito não é a enunciação do falso ${ }^{5}$ propriamente, pois a própria falsidade e a verdade fazem parte de sua estrutura e nela mesma se confundem. O mito possui seu próprio mundo significativo, onde tais classificações não se encontram. Segundo Edelstein, apesar do mito para Platão ser como uma fábula construída pela vontade ele não é uma antítese da razão (EDELSTEIN, 1949, p. 466). Ou seja, em sua função, o mito não se opõe ao lógos. De acordo Luc Brisson, "Platão quer colocar o lógos no lugar do mŷthos, mas deve levar em consideração o segundo para dar um fundamento ao primeiro e garantir sua eficácia." (BRISSON, 2003, p. 27).

O amor é retratado como um grande intermediário entre o divino e o humano, aquele que faz a ligação e permite aos homens a capacidade de buscar o seu objeto de desejo, pois "sendo Éros amante do belo, necessariamente será filósofo ou amante da sabedoria, e, como tal, se encontra colocado entre os sábios e os ignorantes." (Banquete, 204b). Dito isso, Sócrates irá fazer a

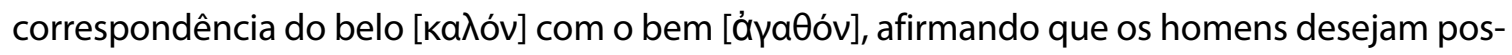
suir as coisas boas para atingir a felicidade, o que estabelece uma relação causal entre bem e felicidade, sendo esta o motivo de desejarmos aquele (Banquete, 204d-205a). Será nesse ponto que Sócrates, através de Diotima, irá fazer uma referência indireta a doutrina de Aristófanes:

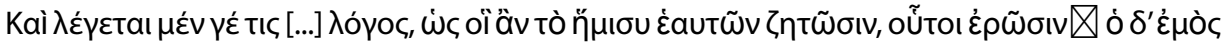

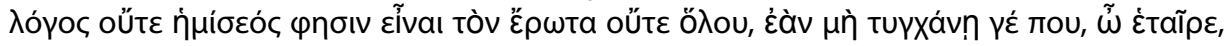
ájäòv őv. Existe uma teoria segundo a qual amar é procurar a outra metade de si mesmo. Porém, o que minha teoria afirma é que amar não será a procura da metade nem do todo, se essa metade, meu caro, e esse todo não forem bons. (Banquete, 205d10-e3).

Dessa maneira, Sócrates conclui dizendo que se deseja o belo porque este é bom e o amor "é o desejo de possuir sempre o bem" (Banquete, 206a). O homem é aquele que busca procriar nas coisas belas e boas para poder se imortalizar nas suas obras. Alguns homens só conseguem produzir filhos do corpo que pouco duram, no entanto, aqueles que conseguem perdurar, produzem filho da alma, verdadeiras obras que tornaram o seu autor imortal. Essa são as etapas estética e ética do discurso de Sócrates que se complementam em vista de uma vida boa e feliz.

Entretanto, será nos mistérios últimos que Diotima pretende inserir a etapa mais difícil da educação socrática para o amor (Banquete, 209e et seq.). Será através desses mistérios que

\footnotetext{
${ }^{5}$ Para defender a tese de que o mito não é a enunciação do falso utilizamos os estudos de Edelstein, 1949, p. 469; "Para ser claro, é inerente na natureza do entendimento humano que a verdade e a falsidade são sempre estreitamente entrelaçadas"; e principalmente VEYNE, 1987, onde ele coloca: “O mito e o lógos não se opõem como o erro e a verdade." (p. 13-14); "[...] a tradição mítica transmite um núcleo autêntico que, ao longo dos séculos, se foi rodeando de lendas; só estas lendas é que põem problemas, mas não o núcleo" (p. 27); "O mito era um tertium quid, nem verdadeiro, nem falso" (p. 45); "Conclusão: temos de antemão a certeza de que mesmo o mito mais ingênuo tem um fundo de verdade." (p. 87-88).
} 
Sócrates será introduzido às etapas epistêmica e ôntica de seu discurso. Os degraus eróticos de Diotima são a passagem do belo sensível para a Forma do Belo, definida como aủtò ka $\theta^{\prime}$ aưtò

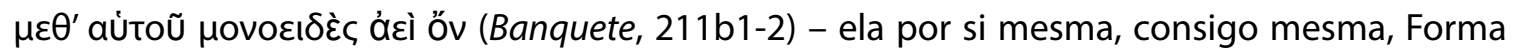
única, sempre sendo -, do qual todas as outras coisas belas participam. No Fedro, há o mesmo impulso erótico para o conhecimento da Forma do Belo ou Beleza, para que assim se possa atingir o bem e a felicidade, pois existe a mesma relação no Banquete entre a beleza e o bem. A beleza exerce a função no discurso de conduzir os iniciados pelo amor para a contemplação das demais Formas ou Ideias, sendo estas o verdadeiro objeto de desejo do filósofo. A beleza no seu papel sensível possui certa semelhança com o papel do mito. Enquanto este pretende convencer a parte mais baixa da alma a acreditar no que é contado, exercendo junto do elemento racional uma função persuasiva/educativa, aquela pretende a partir do sensível conduzir ao inteligível através de um exercício erótico/pedagógico. A visão é posta no discurso como a mais agudas das sensações, pois permite a contemplação da beleza e, com isto, o engate inicial para que se possa conduzir a alma para a contemplação das Formas supracelestes, unicamente captadas pelo intelecto. Somente aqueles que são de alguma maneira iniciados e não se deixam cair no prazer imediato despertado ao ver a beleza, podem retirar dela os devidos proveitos. A beleza é a única coisa do divino que conseguimos captar pelo sensível. Nenhuma outra virtude, nada mais divino, senão a beleza. Ela é capaz de excitar os sentidos do corpo e conduzir ao desvelamento dos mistérios da alma, permitindo que a reminiscência se instale e se inicie a lembrança das Formas.

Em paralelo com os degraus eróticos de Diotima indicados no Banquete (210a-211e), os mistérios no Fedro vão se revelando aos poucos ao amado conduzido pelo caminho indicado pelo mestre (amante). Aqueles que fazem o reto uso de suas recordações do divino despertadas pela contemplação da beleza, recebem pelos olhos o afluxo da beleza, suas asas são irrigadas e novamente começam a nascer. Os olhos são a janela natural da alma (Fedro, 255c), a entrada onde se estabelece a relação do sensível com o inteligível. Platão indica a necessidade de uma experiência vital com a beleza para que se possa estabelecer uma correspondência com o inteligível. A beleza deve ser vivenciada, apreciada e contemplada, pois ela é a única Forma que possui uma correspondência sensível. É a que menor esforço exige para que seja apreendida, pois, para se experimentá-la, não é necessário um movimento do intelecto. O exercício intelectual é aquele utilizado para o entendimento, e será somente através do intelecto que poderemos entender a beleza em sua Forma absoluta, tanto quanto as demais virtudes. Mas, para que isso ocorra, é preciso que antes possa haver a experimentação, que no caso da beleza acontece pela captação dos olhos. A visão está para o sensível assim como o intelecto está para o inteligível. Ambos estabelecem o paralelo da visibilidade em cada um dos campos em que agem. A beleza por sua vez tem a função de tornar visível o divino, pois age no campo do sensível excitando os sentidos para a reminiscência da Forma de Beleza que se encontram num campo suprassensível. Dentro do percurso mítico que se apresenta, a beleza exerce o recurso persuasivo que é o de conduzir-nos para o inteligível partindo de um meio sensível. Se provarmos que pela existência da beleza no sensível existe também um correspondente de beleza no inteligível, podemos provar a existência das demais Formas supracelestes. Em seu mito sobre a alma (Fedro, 243e9-257b6), Sócrates pretende não só demonstrar a natureza da alma, como também a relação entre o sensível e o inteligível através da beleza. É preciso que se entenda que não é por existir algo sensível que existe algo inteligível, mas justamente o contrário. As Formas supracelestes sempre existiram, são eternas. São também causa da beleza sensível, e é através do exercício da reminiscência que é possível recordar delas no plano sensível. Mas a única maneira de tornar este exercício viável é através da contemplação adequada da beleza. 
O paralelo com o Banquete é singular. Quando Diotima inicia Sócrates nos mistérios eróticos, Sócrates aprende o sentido de éros para se atingir a verdade sobre as coisas que são no mundo. O desejo erótico é o despertar do sensível para o conhecimento das coisas no inteligível.

\section{Considerações finais}

Em nosso artigo, fizemos uma comparação entre os discursos de Aristófanes e Sócrates no Banquete. Em Aristófanes podemos ver um amor voltado para o possível existente no mundo. Apesar dessa busca ser feita na sensibilidade, o todo erótico que se pretende alcançar é de origem metafísica e só pode ser atingido pela relação dos três sentidos de éros expostos em nosso trabalho: desejo sexual, afeição e preferência.

No discurso de Sócrates percebemos um rompimento com a sensibilidade estética de éros rumo a investigação ôntica e epistêmica do sentido último do Amor que seria a contemplação das Formas que só podem ser atingidas no âmbito inteligível. Sócrates irá se apoiar no discurso de Diotima para fundamentar o seu próprio e definir o sentido de éros dentro da filosofia platônica.

Ambos os discursos são complementares. Enquanto Aristófanes aponta uma separação ontológica das partes rumo ao todo, Sócrates aponto na direção de que o todo almejado tem uma relação direta com o Bem e somente através deste se poderia atingir a verdadeira felicidade ${ }^{6}$.

\section{Bibliografia}

\section{Edições e traduções do Banquete}

AZEVEDO, M. T. S. O Banquete. Tradução de Maria Teresa Schiappa de Azevedo. Lisboa: Edições 70, 2001.

BURNET, J. Platonis Opera, recognovit brevique adnotatione critica instrvxit: loannes Burnet, Tomvs II. Oxford: Oxford University Press, 1901.

NUNES, C. A. O Banquete. Tradução de Carlos Alberto Nunes. Belém: EDUFPA, 2001.

\section{Estudos}

BRISSON, Luc. A Religião como Fundamento da Reflexão Filosófica e como meio de Ação Política nas Leis de Platão. Kriterion, n. 107, p.24-38, 2003.

DOVER, K. J. Aristophanes' Speech in Plato's Symposium. Journal of Hellenic Studies, v. 86, p. 41$50,1966$.

EDELSTEIN, L. The Function of the Myth in Plato's Philosophy. Journal of the History of Ideas, v. 10, n. 4, 1949, p. 469.

HALPERIN, D. M. Love's Irony: Six Remarks on Platonic Eros. In: BARTSCH, S.; BARTSCHERER, T. Erotikon: Essays on Eros, Ancient and Modern. Chicago: University of Chicago Press, 2005, p. 48-58.

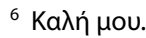


MORGAN, K. Myth and Philosophy. From Presocratics to Plato. Cambridge: Cambridge University Press, 2004.

NICHOLS, M. P. Socrates' Contest with the Poets in Plato's Symposium. Political Theory, v. 32, n. 2, p. 186-206, 2004.

SWITZER, Robert. The Topology of Madness: Philosophic Seduction in Plato's Phaedrus. Alif: Journal of Comparative Poetics, n. 14, p. 6-36, 1994.

VEYNE, P. Acreditaram os Gregos nos seus Mitos? Tradução de António Gonçalves. Lisboa: Edições 70, 1987.

\section{Sobre o autor}

Luiz Maurício Bentim da Rocha Menezes

Doutor em Filosofia (UFRJ) e professor de Filosofia Antiga do Instituto Federal do Triângulo Mineiro (IFTM).

Recebido em: 20/11/2019

Aprovado em: 23/2/2020 